[Chem. Pharm. Bull.

35( 4 )1579-1586(1987)]

\title{
Metabolism of 2,4-Dinitrotoluene, 2,4-Dinitrobenzyl Alcohol and 2,4-Dinitrobenzaldehyde by Rat Liver Microsomal and Cytosol Fractions
}

\author{
Mrki Shoji, ${ }^{*, a}$ MaSa-AKi Mori, ${ }^{b}$ Tadashi Kawajiri, ${ }^{b}$ Michio Sayama, ${ }^{b}$ \\ YoshiHiro MOri ${ }^{b}$ TATSURO MiYahara, $^{b}$ TAKASHI HONDA ${ }^{c}$ \\ and Hiroshi KOZUKA ${ }^{b}$
}

Radioisotope Laboratory, ${ }^{a}$ Faculty of Pharmaceutical Sciences, ${ }^{b}$ and School of Medicine, ${ }^{c}$ Toyama Medical and Pharmaceutical University, 2630 Sugitani, Toyama 930-01, Japan

(Received August 28, 1986)

\begin{abstract}
The metabolism of 2,4-dinitrotoluene (2,4-DNT), 2,4-dinitrobenzyl alcohol (2,4-DNB) and 2,4-dinitrobenzaldehyde (2,4-DNAl) in rat liver microsomal and cytosol fractions was investigated. The objectives of these studies were to determine whether 2,4-DNAl, a potent mutagen, is produced in the oxidation of 2,4-DNB to 2,4-DNBA and to clarify the nature of the enzymes responsible for the oxidation of 2,4-DNT to 2,4-DNB, 2,4-DNAl and 2,4-dinitrobenzoic acid (2,4-DNBA). Data obtained from high-performance liquid chromatography indicated that the major products of 2,4DNT, 2,4-DNB and 2,4-DNAl in the microsomal and cytosol preparations were 2,4-DNB, 2,4DNAl, and 2,4-DNBA and 2,4-DNB, respectively. The results indicate that 2,4-DNAl is an intermediate in the oxidation of 2,4-DNB to 2,4-DNBA. In addition, data obtained by incubating 2,4-DNT, 2,4-DNB or 2,4-DNAl with microsomal or cytosol fraction under air, nitrogen and various concentrations of $\mathrm{CO}$ in oxygen, using cofactors nicotinamide adenine dinucleotide phosphate and reduced nicotinamide adenine dinucleotide phosphate $[\mathrm{NAD}(\mathrm{P})$ and $\mathrm{NAD}(\mathrm{P}) \mathrm{H}]$ and inhibitors (SKF-525A, dimethyl sulfoxide, chloral hydrate, allopurinol, pyrazole and $o$ phenanthroline) suggest that: (a) oxidation of 2,4-DNT to 2,4-DNB is mediated by microsomal P450 ; (b) oxidation of 2,4-DNB to 2,4-DNAl is mediated mainly by cytochrome P-450 and NADdependent alcohol dehydrogenase; (c) oxidation of 2,4-DNAl to 2,4-DNBA and reduction of 2,4DNAl to 2,4-DNB may be mediated by NAD(P)-dependent aldehyde dehydrogenases and NAD(P)H-dependent aldehyde reductases, respectively. These results indicate that 2,4-DNT is metabolized stepwise to 2,4-DNB, 2,4-DNAl and 2,4-DNBA in the rat liver and suggest that the oxidation of 2,4-DNB to 2,4-DNAl is a metabolic activation of 2,4-DNT and that the microsomal cytochrome P-450 and alcohol dehydrogenase may play an important role in the metabolic activation of 2,4-DNT.
\end{abstract}

Keywords_-2,4-dinitrotoluene; 2,4-dinitrobenzyl alcohol; 2,4-dinitrobenzaldehyde; 2,4-dinitrobenzoic acid; metabolism; microsomal cytochrome P-450; cytosol; alcohol dehydrogenase; aldehyde dehydrogenase; aldehyde reductase

2,4-Dinitrotoluene $(2,4-\mathrm{DNT})$ is a major constituent of technical grade DNT $(75 \% 2,4$ DNT, $20 \% 2,6$-DNT, $5 \%$ other isomers) which is a precursor of toluenediisocyanate, used in the manufacture of polyurethane foams and elastomers. ${ }^{1)}$ Although technical grade DNT, ${ }^{2)}$ 2,4-DNT ${ }^{3)}$ and 2,6-DNT ${ }^{4)}$ have been shown to produce hepatocellular carcinomas when administered in the diet of rats, unequivocal mutagenic activity of DNT isomers has not been detected in the Ames assay using histidine-requiring Salmonella typhimurium strains with or without S9 mix. ${ }^{5}$ These findings suggest that the metabolic activation of DNT is very complicated. Rickert et al. proposed a hypothesis for the metabolism and toxicity of DNT isomers: the activation of DNT requires biotransformation to dinitrobenzyl alcohol glucuronide, excretion in the bile, deconjugation, further metabolism by intestinal microorganisms 
and reabsorption, and the reabsorbed metabolites are presumably converted to toxic metabolites. ${ }^{1)}$

We have reported that the urinary major metabolites of 2,4-DNT in rats are 2,4dinitrobenzyl alcohol (2,4-DNB) and 2,4-dinitrobenzoic acid (2,4-DNBA), ${ }^{6}$ and that 2,4dinitrobenzaldehyde (2,4-DNAl), which is not detected as a urinary metabolite of 2,4-DNT, is a direct potent mutagen (about 10000 his $^{+}$revertants $/ \mu$ mol) in the Ames assay using Salmonella typhimurium strains TA 98 and TA $100 .^{7)}$ As 2,4-DNAl is considered to be a possible intermediate in the oxidation of 2,4 -DNB to 2,4 -DNBA, it is worth investigating the oxidative metabolism of 2,4-DNT in rat liver in order to understand the metabolic activation of the agent. In the present study, we have examined the metabolism of 2,4-DNT, 2,4-DNB and 2,4-DNAl by using hepatic microsomal and cytosol fractions prepared from rats pretreated with phenobarbital (PB) and 5,6-benzoflavone (BF). Experiments were performed with various inhibitors under air, nitrogen and various concentrations of $\mathrm{CO}$ in oxygen to assess the nature of the enzymes responsible for the consecutive oxidations of 2,4-DNT.

\section{Experimental}

Chemicals-2,4-DNT and 2,4-DNBA ( $>99 \%$ chromatographically pure after recrystallization from methanol) were obtained from Wako Pure Chemical Industries Ltd. 2,4-DNAl ( $>98 \%$ pure) was obtained from Aldrich Chemical Co. 2,4-DNB was prepared as previously described. ${ }^{8)} \beta$-Diethylaminoethyl diphenyl- $n$-propylacetate hydrochloride (SKF-525A) was a gift from Prof. H. Yoshimura, Kyushu University (Japan). Other chemicals were obtained from the following sources: dimethyl sulfoxide (DMSO, ultra grade), PB, BF, chloral hydrate, allopurinol, pyrazole and $o$-phenanthroline from Wako Pure Chemical Industries Ltd.; reduced nicotinamide adenine dinucleotide phosphate (NADPH), reduced nicotinamide adenine dinucleotide (NADH), NADP, NAD and alcohol dehydrogenase $(345 \mathrm{IU} / \mathrm{mg}$ protein, from yeast) from Oriental Yeast Co., Ltd; tetra- $n$-butylammonium chloride (TBACl) from Nakarai Chemicals Ltd. Solvents used were of the highest grade commercially available.

Preparation of Liver Fractions — Male Sprague-Dawley rats (160-180 g) obtained from Sankyo Laboratories Co. were pretreated with PB ( $80 \mathrm{mg} / \mathrm{kg}$ in $0.9 \% \mathrm{NaCl}$, i.p., $96,72,48$ and $24 \mathrm{~h}$ before death) and $\mathrm{BF}(80 \mathrm{mg} / \mathrm{kg}$ in corn oil, i.p., $48 \mathrm{~h}$ before death) in a similar manner to that used for pretreatment in the case of hepatic preparations used for the assay of mutagenicity. ${ }^{7)}$ Animals were killed by decapitation. The livers were removed, minced and homogenized in three volumes of ice-cold $1.15 \% \mathrm{KCl}$. The microsomal and cytosol fractions were prepared by differential centrifugation as previously described. ${ }^{9)}$ Protein was determined by the method of Lowry et al. ${ }^{10)}$ with bovine serum albumin as a standard.

Incubation of Enzyme Preparations with 2,4-DNT, 2,4-DNB and 2,4-DNAI-Standard incubation mixtures $\left(2 \mathrm{ml}\right.$ ) contained $65 \mathrm{~mm}$ phosphate buffer ( $\mathrm{pH} 7.4$ ), $4 \mathrm{~mm}$ cofactors (NADPH, NADH, NADP or NAD in $\mathrm{H}_{2} \mathrm{O}$ ), $1 \mathrm{~mm}$ substrates (2,4-DNT, 2,4-DNB or 2,4-DNAl in DMSO or acetone) and 2.2 or $2.7 \mathrm{mg}$ of microsomal or cytosol proteins. In some experiments, 0.1 to $5 \mathrm{~mm}$ inhibitor (SKF-525A, DMSO, chloral hydrate, pyrazole, allopurinol or $o$ phenanthroline) was added. The incubations were carried out at $37 \mathrm{C}$ for 5 to $60 \mathrm{~min}$ under air, nitrogen or various concentrations of $\mathrm{CO}$ in oxygen. The $\mathrm{CO}-\mathrm{O}_{2}$ mixtures were prepared in gas burettes and passed into Thunberg vessels containing the reaction mixtures. The incubations were terminated by addition of $0.2 \mathrm{ml}$ of $0.5 \mathrm{~N} \mathrm{HCl}$ followed by the addition of $10 \mathrm{ml}$ of ether.

Analysis of Metabolites Produced in 2,4-DNT, 2,4-DNB or 2,4-DNAl Metabolism by High-Performance Liquid Chromatography (HPLC)-Incubation mixtures from triplicate reaction tubes were extracted three times with $10 \mathrm{ml}$ of ether. The ether layer was dried over anhydrous $\mathrm{Na}_{2} \mathrm{SO}_{4}$, and the solvent was evaporated off under an $\mathrm{N}_{2}$ stream and reconstituted in $5 \mathrm{ml}$ of $40 \%$ methanol solution. Then $10 \mu \mathrm{l}$ of this solution was injected into a highperformance liquid chromatograph equipped with a multi-wavelength ultraviolet (UV) monitor (Hitachi model 655). The reversed-phase column used was TSK gel ODS-80TM $(150 \times 4.6 \mathrm{~mm}$ i.d., particle size $5 \mu \mathrm{m}$, Toyo Soda Kogyo Co.). The mobile phase used was $40 \%$ methanol in $0.18 \mathrm{~mm} \mathrm{TBACl}$. HPLC operating conditions were as follows: flow rate, $1.0 \mathrm{ml} / \mathrm{min}$; UV monitor, $250 \mathrm{~nm}$; column temperature, ambient. Under these conditions, 2,4-DNT, 2, 4-DNB, 2,4-DNAl and 2,4-DNBA gave retention times of 20.2, 8.6, 11.3 and $4.7 \mathrm{~min}$, respectively. Quantities of metabolites were determined from standard curves plotted as peak area is. amount of standard injected. The range of concentrations used in determination of the standard curves was $0.15-2.8 \mathrm{ng} / \mu \mathrm{l}$. Standard curves generated were linear over the concentration range measured $(r=0.999)$ with no more than $5 \%$ variability between replicate samples. The amounts of metabolites were expressed as nanomoles produced per milligram of protein or gram of liver. 


\section{Results}

The detection of metabolites was carried out by comparing the chromatograms of incubated samples with those of blanks, and by the co-chromatography of incubated samples with authentic samples. Table I shows the products detected chromatographically in the

TABLE I. Metabolites Detected by HPLC in the Hepatic Metabolism of 2,4-DNT, 2,4-DNB and 2,4-DNAl

\begin{tabular}{|c|c|c|c|c|c|}
\hline \multirow{2}{*}{ Substrate } & \multicolumn{2}{|c|}{ Incubation system } & \multirow{2}{*}{ Metabolite } & \multirow{2}{*}{$\begin{array}{l}\text { Retention } \\
\text { time (min) }\end{array}$} & \multirow{2}{*}{$\frac{\text { Activity }}{\mathrm{nmol} / \mathrm{g} \text { liver } / \mathrm{min}}$} \\
\hline & $\begin{array}{l}\text { Enzyme } \\
\text { source }\end{array}$ & Cofactor & & & \\
\hline \multirow[t]{4}{*}{ 2,4-DNT } & \multirow[t]{4}{*}{ MS } & NADH & 2,4-DNB & 8.6 & $8.60 \pm 0.49$ \\
\hline & & NADPH & 2,4-DNB & 8.6 & $64.48 \pm 1.62$ \\
\hline & & $\begin{array}{l}\mathrm{NADH}+ \\
\text { NADPH }\end{array}$ & 2,4-DNB & 8.6 & $74.68 \pm 1.19$ \\
\hline & & $\begin{array}{l}\text { NAD or } \\
\text { NADP }\end{array}$ & n.d. & - & - \\
\hline \multirow[t]{20}{*}{$2,4-\mathrm{DNB}$} & \multirow[t]{4}{*}{ MS } & NADH & 2,4-DNAl & 11.3 & $4.10 \pm 0.78$ \\
\hline & & NADPH & 2,4-DNAl & 11.3 & $7.45 \pm 0.86$ \\
\hline & & NAD & 2,4-DNAl & 11.3 & $2.95 \pm 0.44$ \\
\hline & & NADP & 2,4-DNAl & 11.3 & $3.73 \pm 0.68$ \\
\hline & \multirow[t]{4}{*}{ CS } & NADH & 2,4-DNAl & 11.3 & $8.54 \pm 0.76$ \\
\hline & & NADPH & 2,4-DNAl & 11.3 & $7.48 \pm 1.23$ \\
\hline & & NAD & 2,4-DNAl & 11.3 & $17.63 \pm 2.86$ \\
\hline & & NADP & 2,4-DNAl & 11.3 & $18.87 \pm 3.21$ \\
\hline & \multirow[t]{12}{*}{ MS } & NAD & 2,4-DNBA & 4.7 & $60.30 \pm 1.52$ \\
\hline & & & 2,4-DNB & 8.6 & $4.12 \pm 0.78$ \\
\hline & & & Unknown & 3.1 & - \\
\hline & & NADP & 2,4-DNBA & 4.7 & $60.59 \pm 4.23$ \\
\hline & & & 2,4-DNB & 8.6 & $1.29 \pm 0.32$ \\
\hline & & & Unknown & 3.1 & - \\
\hline & & $\mathrm{NADH}$ & 2,4-DNBA & 4.7 & $6.89 \pm 0.91$ \\
\hline & & & 2,4-DNB & 8.6 & $24.57 \pm 1.25$ \\
\hline & & & Unknown & 5.3 & - \\
\hline & & NADPH & 2,4-DNBA & 4.7 & $1.58 \pm 0.10$ \\
\hline & & & 2,4-DNB & 8.6 & $5.01 \pm 0.19$ \\
\hline & & & Unknown & 5.3 & - \\
\hline \multirow[t]{10}{*}{ 2,4-DNAl } & \multirow[t]{10}{*}{$\mathrm{CS}$} & NAD & 2,4-DNBA & 4.7 & $64.53 \pm 4.60$ \\
\hline & & & $2,4-\mathrm{DNB}$ & 8.6 & $7.76 \pm 0.09$ \\
\hline & & NADP & 2,4-DNBA & 4.7 & $13.98 \pm 0.43$ \\
\hline & & & 2,4-DNB & 8.6 & $1.00 \pm 0.02$ \\
\hline & & $\mathrm{NADH}$ & 2,4-DNBA & 4.7 & $52.19 \pm 7.03$ \\
\hline & & & 2,4-DNB & 8.6 & $109.02 \pm 0.88$ \\
\hline & & & Unknown & 3.1 & - \\
\hline & & NADPH & 2,4-DNBA & 4.7 & $15.18 \pm 2.46$ \\
\hline & & & 2,4-DNB & 8.6 & $320.29 \pm 7.89$ \\
\hline & & & Unknown & 3.1 & - \\
\hline
\end{tabular}

Incubation mixtures $(2 \mathrm{ml})$ contained $65 \mathrm{~mm}$ phosphate buffer $(\mathrm{pH} 7.4), 4 \mathrm{~mm}$ cofactor, $1 \mathrm{~mm}$ substrate and 2.2 or $2.7 \mathrm{mg}$ of microsomal or cytosol proteins. Incubations were carried out at $37^{\circ} \mathrm{C}$ for $15 \mathrm{~min}$ under air. HPLC operating conditions were as follows: column, TSK gel ODS-80TM; mobile phase, $40 \% \mathrm{MeOH}$ in $0.18 \mathrm{~mm} \mathrm{TBACl}$; flow rate, $1.0 \mathrm{ml} / \mathrm{min}$; UV monitor, $250 \mathrm{~nm}$; column temperature, ambient. Values are means \pm S.D. for three samples. n.d., not detected; MS, microsomes; CS, cytosol; 2,4-DNT, 2,4-dinitrotoluene; 2,4-DNB, 2,4-dinitrobenzyl alcohol; 2,4-DNAl, 2,4-dinitrobenzaldehyde; 2,4-DNBA, 2,4-dinitrobenzoic acid. 
metabolism of 2,4-DNT, 2,4-DNB or 2,4-DNAl by hepatic microsomal or cytosol preparations. The detection limit of each compound in this experiment was $1.0 \mathrm{ng}$. No peaks corresponding to metabolites were detected after incubating substrates with heat-in-activated (90 C, $10 \mathrm{~min}$ ) microsomes or cytosol, or without microsomes or cytosol (chromatograms not shown).

The metabolite produced by incubation of 2,4-DNT with microsomal preparations was 2,4-DNB (Table I). This enzyme reaction required reduced forms of pyridine nucleotides, of which NADPH was much more effective than NADH as a cofactor. Synergism of the two cofactors was seen under these experimental conditions. No metabolites were produced by incubating 2,4-DNT with cytosol instead of microsomes as an enzyme source (data not shown). The rate of 2,4-DNT oxidation to 2,4-DNB was nearly linear with respect to microsomal protein concentration $(0$ to $1 \mathrm{mg} / \mathrm{ml})$, NADPH concentration ( 0 to $4 \mathrm{~mm})$, incubation time ( 0 to $30 \mathrm{~min}$ ) and substrate concentration ( 0 to $0.4 \mathrm{~mm}$ ). The rate reached a plateau at $5 \mathrm{mg} / \mathrm{ml}$ protein concentration, $6 \mathrm{~mm}$ NADPH concentration, 60 min incubation time and $0.6 \mathrm{~mm}$ substrate concentration. The oxidation of 2,4-DNT to 2,4-DNB by NADPH-dependent microsomal enzyme was almost completely inhibited in an atmosphere of

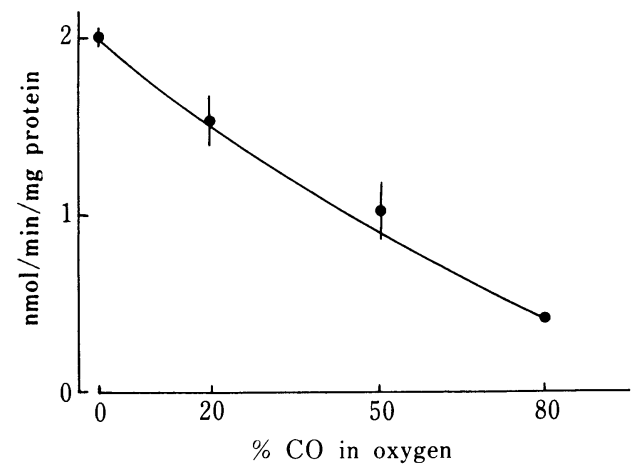

Fig. 1. Effect of $\mathrm{CO}$ on Microsomal NADPHDependent Oxidation of 2,4-DNT to 2,4-DNB

Incubation mixtures $(2 \mathrm{ml})$ contained $65 \mathrm{~mm}$ phosphate buffer ( $\mathrm{pH} 7.4$ ), 4 mM NADPH, 1 mм 2,4-DNT and $2.2 \mathrm{mg}$ of microsomal protein. Incubations were carried out at $37^{\circ} \mathrm{C}$ for $15 \mathrm{~min}$ under various $\mathrm{CO}$ concentrations. Each point represents the mean \pm S.D. of three samples.
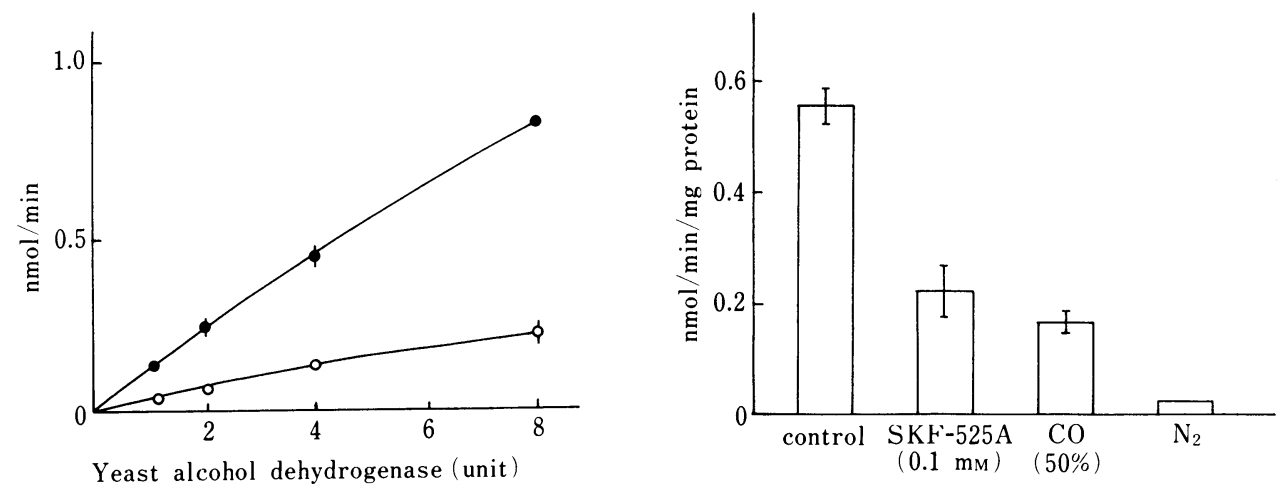

Fig. 2. Oxidation of 2,4-DNB to 2,4-DNAl by Yeast Alcohol Dehydrogenase Requiring NAD

Incubation mixtures $(2 \mathrm{ml})$ contained $65 \mathrm{~mm}$ phosphate buffer $(\mathrm{pH} 7.4), 4 \mathrm{~mm}$ NAD or NADP, $1 \mathrm{~mm}$ 2,4-DNAl, and 1 to 8 units of yeast alcohol dehydrogenase. Incubations were carried out at $37 \mathrm{C}$ for 20 min under air. Each point represents the mean \pm S.D. of three samples.

- - NAD; - O-, NADP.

Fig. 3. Effects of SKF-525A, CO and $\mathrm{N}_{2}$ on Microsomal NADPH-Dependent Oxidation of 2,4-DNB to 2,4-DNAl

Incubation mixtures $(2 \mathrm{ml})$ contained $65 \mathrm{~mm}$ phosphate buffer ( $\mathrm{pH} 7.4$ ), $4 \mathrm{~mm}$ NADPH, 1 mм 2,4-DNB, $2.2 \mathrm{mg}$ of microsomal protein and 0 or $0.1 \mathrm{mM}$ SKF$525 \mathrm{~A}$. Incubations were carried out at $37 \mathrm{C}$ for 20 min under air, $50 \% \mathrm{CO}$ in oxygen or $\mathrm{N}_{2}$. Each bar represents the mean \pm S.D. of three samples. 
nitrogen (data not shown). In addition, this oxidation was inhibited by about 25,50 and $80 \%$, respectively, in atmospheres of 20,50 and $80 \%$ of $\mathrm{CO}$ in oxygen (Fig. 1) and inhibited by about $85 \%$ by a low concentration $(0.1 \mathrm{~mm})$ of SKF-525A, an inhibitor of cytochrome P-450 dependent monooxygenase. ${ }^{11)}$ These findings indicate that the oxidation of 2,4-DNT to 2,4DNB is mediated by hepatic microsomal cytochrome P-450.

The production of 2,4-DNAl from 2,4-DNB was mainly dependent on the cytosol preparations containing $\mathrm{NAD}(\mathrm{P})$ and microsomal preparation containing NADPH as a cofactor (Table I). The 2,4-DNB oxidation to 2,4-DNAl by cytosol preparation containing NAD was inhibited by about 50 and $40 \%$ by addition of $1 \mathrm{~mm} \mathrm{DMSO}^{12)}$ and $5 \mathrm{~mm} o-$ phenanthroline, ${ }^{13)}$ inhibitors of NAD-dependent alcohol dehydrogenase, but this oxidation was not inhibited by addition of $1 \mathrm{~mm}$ pyrazole, ${ }^{13)}$ an inhibitor of alcohol dehydrogenase (data not shown). In addition, this oxidation was mediated by yeast alcohol dehydrogenase, requiring NAD as a cofactor (Fig. 2). The 2,4-DNB oxidation to 2,4-DNAl by cytosolic preparation containing NADP was not inhibited by DMSO, $o$-phenanthroline or pyrazole (data not shown). Therefore, it seems that the NADP-dependent activity may differ from the NAD-dependent activity. Further characterization of the NAD(P)-dependent activities was not attempted. The 2,4-DNB oxidation to 2,4-DNAl by microsomal preparation containing NADPH was inhibited by about 60,70 and $95 \%$ by addition of $0.1 \mathrm{~mm}$ SKF-525A and in the

TABLE II. Effect of Chloral Hydrate on Microsomal and Cytosol NAD(P)-Dependent Oxidations of 2,4-DNAl to 2,4-DNBA

\begin{tabular}{|c|c|c|c|c|}
\hline \multirow{2}{*}{\multicolumn{2}{|c|}{ Inhibitor (mM) }} & \multicolumn{2}{|c|}{ Incubation system } & \multirow{2}{*}{ Percent inhibition } \\
\hline & & Enzyme source & Cofactor & \\
\hline \multirow[t]{8}{*}{ Chloral hydrate } & $(0.5)$ & $\mathrm{CS}$ & NAD & $5.3 \pm 2.8$ \\
\hline & & & NADP & $42.8 \pm 6.8$ \\
\hline & & MS & NAD & $28.5 \pm 4.6$ \\
\hline & & & NADP & $42.5 \pm 6.7$ \\
\hline & $(1.0)$ & $\mathrm{CS}$ & NAD & $8.6 \pm 1.9$ \\
\hline & & & NADP & $63.2 \pm 5.9$ \\
\hline & & MS & NAD & $50.2 \pm 4.8$ \\
\hline & & & NADP & $78.5 \pm 7.2$ \\
\hline
\end{tabular}

Incubation mixtures $(2.0 \mathrm{ml})$ contained $65 \mathrm{~mm}$ phosphate buffer $(\mathrm{pH} 7.4), 4 \mathrm{~mm}$ NAD or NADP, $1 \mathrm{~mm}$ 2,4-DNAl, 0.5 or $1.0 \mathrm{~mm}$ chloral hydrate and 2.2 or $2.7 \mathrm{mg}$ of microsomal or cytosol proteins. Incubations were carried out at $37^{\circ} \mathrm{C}$ for $20 \mathrm{~min}$ under room air. Results are expressed as percent inhibition of 2,4-DNBA production. Values are means \pm S.D. for three samples.

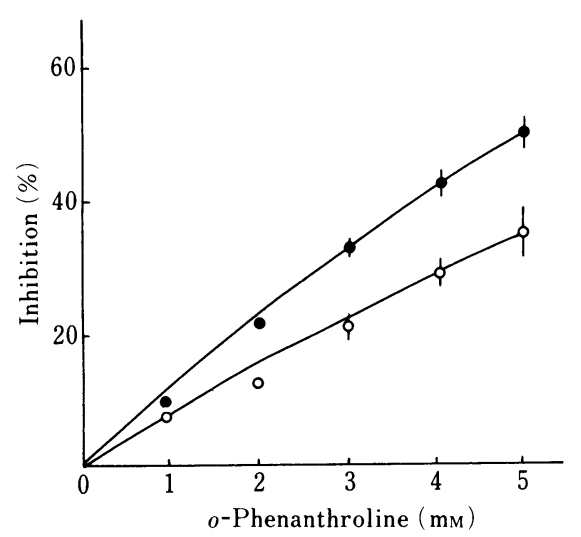

Fig. 4. Effect of $o$-Phenanthroline on Microsomal and Cytosol NADH-Dependent Reductions of 2,4-DNAl to 2,4-DNB

Incubation mixtures $(2 \mathrm{ml})$ contained $65 \mathrm{~mm}$ phosphate buffer ( $\mathrm{pH} 7.4$ ), $4 \mathrm{~mm}$ NADH, $1 \mathrm{~mm}$ 2,4-DNAl, 2.2 or $2.7 \mathrm{mg}$ of microsomal or cytosol proteins and 0 or 1 to $5 \mathrm{~mm} o$-phenanthroline. Incubations were carried out at $37^{\circ} \mathrm{C}$ for 20 min under air. Each point represents the mean \pm S.D. of three samples. $-\mathrm{O}-$, microsomes; - - cytosol. 
atmospheres of $50 \% \mathrm{CO}$ in oxygen or nitrogen (Fig. 3). These findings strongly suggest that a large proportion of 2,4-DNB oxidation to 2,4-DNAl is mediated by both NAD-dependent alcohol dehydrogenase and microsomal cytochrome P-450 but a part of that may be due to NADP-dependent cytosolic dehydrogenase.

When 2,4-DNAl was incubated with cytosol or microsomal preparations containing oxidized and reduced forms of pyridine nucleotides, it was found to be metabolized to 2,4DNBA and 2,4-DNB, and two unknown metabolites with retention times of 3.1 or $5.3 \mathrm{~min}$ (Table I, chromatograms not shown). Characterization of the unknown compounds was not attempted. The oxidation of 2,4-DNAl to 2,4-DNBA was mainly dependent on the cytosol and microsomal preparations containing oxidized forms of pyridine nucleotides. The 2,4DNAl oxidation to 2,4-DNBA was inhibited partially by chloral hydrate, an inhibitor of NAD(P)-dependent aldehyde dehydrogenases ${ }^{14)}$ (Table II). However, allopurinol, an inhibitor of xanthine oxidase, which is a dehydrogenase requiring NAD as a cofactor, ${ }^{15)}$ did not inhibit the 2,4-DNAl oxidation to 2,4-DNBA (data not shown). These findings suggest the participation of $\mathrm{NAD}(\mathrm{P})$-dependent aldehyde dehydrogenases in the 2,4-DNAl oxidation to 2,4 -DNBA. The reduction of 2,4-DNAl to 2,4-DNB was dependent on the cytosol and microsomal preparations containing reduced forms of pyridine nucleotides (Table I). The 2,4DNAl reduction to 2,4-DNB by cytosol and microsomal preparations containing NADH was inhibited by about 50 and $35 \%$, respectively, by $5 \mathrm{~mm} o$-phenanthroline (Fig. 4).

\section{Discussion}

The present investigations have demonstrated that: (a) the metabolites of 2,4-DNT, 2,4DNB and 2,4-DNAl produced by hepatic preparations are 2,4-DNB, 2,4-DNAl and 2,4DNBA; (b) 2,4-DNT oxidation to 2,4-DNB can be accomplished by microsomal cytochrome P-450 dependent monooxygenase; (c) 2,4-DNB oxidation to 2,4-DNAl is mediated by either alcohol dehydrogenase or cytochrome P-450; (d) 2,4-DNAl oxidation to 2,4-DNBA is mediated by aldehyde dehydrogenases and aldehyde oxidases; (e) 2,4-DNAl reduction to 2,4DNB is mediated by aldehyde reductases. Based on these results, the probable hepatic metabolism of 2,4-DNT in the rat can be summarized as follows (Chart 1).

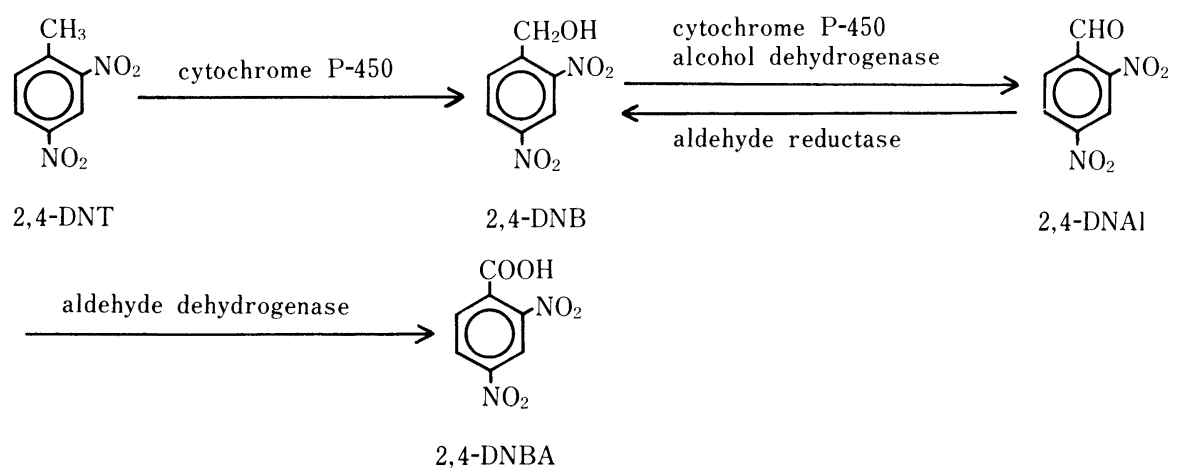

Chart 1. Hepatic Metabolism of 2,4-DNT in the Rat

The finding that the oxidation of 2,4-DNT to 2,4-DNB is mediated by the microsomal cytochrome P-450 of Sprague-Dawley rats is in accord with the result of Decad et al.. ${ }^{16)}$ who have shown the participation of microsomal cytochrome P-450 of Fischer-344 rat liver in the 2,4-DNT oxidation to 2,4-DNB. It seems to be a novel finding that the production of 2,4DNAl from 2,4-DNB is mediated not only by alcohol dehydrogenases but also by cytochrome P-450, since oxidation of alcohol to aldehyde, in general, is mediated by 
dehydrogenases such as alcohol dehydrogenases. In this connection, Watanabe et al. also reported that the microsomal oxidation of 11-hydroxy- $\Delta^{8}$-tetrahydrocannabinol to 11-oxo$4^{8}$-tetrahydrocannabinol is mediated by a mixed function oxidase involving cytochrome P$450 .{ }^{17)}$

Erwin et al. $^{13)}$ showed that an NADH-linked aldehyde reductase mediating the reduction of aliphatic and aromatic aldehydes such as hepataldehyde and $m$-nitrobenzaldehyde was inhibited about $60 \%$ by $5 \mathrm{~mm} o$-phenanthroline, but this reductase was not inhibited by pyrazole. In addition, Tabakoff and Erwin $^{18)}$ and Takahàshi et al. ${ }^{19)}$ reported that a non specific aldehyde reductase requiring NADPH was located in cytosol and microsomal fractions. Therefore, it seems that NAD(P)H-dependent microsomal and cytosolic aldehyde reductases may be responsible for the 2,4-DNAl reduction to 2,4-DNB. Moreover, the NADH-dependent cytosolic aldehyde reductase activity may be attributed to the reverse action of NAD-dependent cytosolic alcohol dehydrogenase, because both NAD- and NADHdependent activities are inhibited by $o$-phenanthroline.

2,4-DNB and 2,4-DNBA were major urinary metabolites of 2,4-DNT in the rat, but 2,4DNAl was not detected in the urine. ${ }^{6}$ However, the finding that 2,4-DNAl can be produced by incubating 2,4-DNB with microsomal and cytosol preparations (Table I and Fig. 3) indicates that 2,4-DNAl is an intermediate in the oxidation of 2,4-DNB to 2,4-DNBA. The discrepancy between in viro and in vitro metabolism may be due to the high activities in the oxidation and reduction of 2,4-DNAl to 2,4-DNBA and 2,4-DNB compared with those in the oxidation of 2,4-DNB to 2,4-DNAl (Table I) and an interaction between 2,4-DNAl and hepatic macromolecules, because compounds containing an aldehyde group damage bacterial deoxyribonucleic acid. ${ }^{5 c)}$ In fact, we have shown that 2,4-DNAl is a potent direct-acting mutagen that does not require metabolic activation in the Ames assay using Salmonella typhimurium. ${ }^{7}$ Thus it seems that the oxidation of 2,4-DNB to 2,4-DNAl, which is mediated by microsomal cytochrome P-450 and alcohol dehydrogenases, may be a metabolic activation of 2,4-DNT in the rat. In addition, the data presented here indicate that the microsomal cytochrome P-450 and cytosolic alcohol dehydrogenase may play an important role in the metabolic activation of 2,4-DNT. $525 \mathrm{~A}$.

Acknowledgments We are grateful to Professor H. Yoshimura of Kyushu University for supplying SKF-

\section{References and Notes}

1) D. E. Rickert, B. E. Butterworth and J. A. Popp, CRC Critical Rev. Toxicol., 13, 217 (1984).

2) Anon., Interim Report, CIIT Docket no. 327N8, Chemical Industry Institute of Toxicology, Research Triangle Park, 1979.

3) H. V. Ellis, J. H. Hagensen, J. R. Hodgson, J. L. Minor, C. B. Hong, E. R. Ellis, J. D. Girvin, D. O. Helton, B. L. Herndon and C. C. Lee, Final Report no. 7, Project 3900-B, Midwest Research Institute, Kansas City, Mo., 1979.

4) J. A. Popp and T. B. Leonard, Proc. Am. Assoc. Cancer Res., 24, 361 (1983).

5) a) D. B. Couch, P. Flowe and D. Ragan, Environ. Mutagenesis, 1, 168 (1978); b) H. Tokiwa, R. Nakagawa and Y. Ohnishi, Mutat. Res., 91, 321 (1981); c) C. W. Chiu, L. H. Lee, C. Y. Wang and T. Bryan, ibid., 58, 11 (1978).

6) M. Shoji, M. Mori, K. Moto-o, H. Kozuka and T. Honda, Chem. Pharm. Bull., 34, 1687 (1985).

7) M. Mori, T. Miyahara, K. Taniguchi, K. Hasegawa, H. Kozuka, M. Miyagoshi and T. Nagayama, Toxicol. Lett., 13, 1 (1982); M. Mori, T. Miyahara, K. Moto-o, M. Fukukawa, H. Kozuka, M. Miyagoshi and T. Nagayama, Chem. Pharm. Bull., 33, 4556 (1985).

8) M. Mori, Y. Naruse and H. Kozuka, Chem. Pharm. Bull., 29, 1147 (1981).

9) M. Mori, T. Matsuhashi, T. Miyahara, S. Shibata, C. İzima and H. Kozuka, Toxicol. Appl. Pharmacol., 76, 105 (1984).

10) O. H. Lowry, N. J. Rosebrough, A. L. Farr and R. J. Randall, J. Biol. Chem., 193, 265 (1951).

11) P. L. Gigon, T. E. Gram and J. R. Gillette, Mol. Pharmacol., 5, 109 (1969).

12) M. Sharkawi and B. Elfassy, Toxicol. Lett., 25, 185 (1985). 
13) V. G. Erwin, W. D. W. Heston and B. Tabakoff, J. Neurochem., 19, 2269 (1972).

14) R. Lindahl and S. Evces, J. Biol. Chem., 259, 11986 (1984).

15) H. H. H. Oei, H. C. Zoganas, J. M. McCord and S. W. Schaffer, Res. Commun. Chem. Pathol. Pharmacol., 51, 195 (1986).

16) G. M. Decad, M. E. Graichen and J. G. Dent, Toxicol. Appl. Pharmacol., 62, 325 (1982).

17) K. Watanabe, I. Yamamoto, K. Oguri and H. Yoshimura, Biochem. Biophys. Res. Commun., 88, 178 (1979).

18) B. Tabakoff and V. G. Erwin, J. Biol. Chem., 245, 3263 (1970).

19) N. Takahashi, T. Saito, Y. Goda and T. Tomita, J. Biochem. (Tokyo), 99, 513 (1986). 